Gut and Liver, Vol. 11, No. 5, September 2017, pp. 579-589

REVIEW

\title{
Gastroparesis Updates on Pathogenesis and Management
}

\author{
Nanlong Liu and Thomas Abell \\ Division of Gastroenterology, Hepatology, and Nutrition, University of Louisville, Louisville, KY, USA
}

Gastroparesis (Gp) is a chronic disease that presents with clinical symptoms of early satiety, bloating, nausea, vomiting, and abdominal pain. Along with these symptoms, an objective finding of delayed gastric emptying, along with a documented absence of gastric outlet obstruction, are required for diagnosis. This article focuses on updates in the pathogenesis and management of Gp. Recent studies on full thickness biopsies of Gp patients have shed light on the complex interactions of the central, autonomic, and enteric nervous systems, which all play key roles in maintaining normal gut motility. The management of Gp has evolved beyond prokinetics and antiemetics with the use of gastric electrical stimulators (GES). In addition, this review aims to introduce the concept of gastroparesis-like syndrome (GLS). GLS helps groups of patients who have the cardinal symptoms of Gp but have a normal or rapid emptying test. Recent tests have shown that patients with Gp and GLS have similar pathophysiology, benefit greatly from GES placement, and likely should be treated in a similar manner. (Gut Liver 2017;11:579-589)

Key Words: Nausea; Vomiting; Gastroparesis; Enteric nervous system; Gastric emptying

\section{INTRODUCTION}

Gastroparesis (Gp) is a clinical syndrome consisting of the principal symptoms of nausea, vomiting, bloating, early satiety, postprandial fullness, and upper abdominal pain. In addition, objective evidence of delayed gastric emptying (GE) and exclusion of mechanical obstruction is required. ${ }^{1}$ A solid-phase gastric scintigraphy is considered the gold standard in objective evidence required for diagnosis. The symptoms of nausea and vomiting are two of the prevalent symptoms in Gp. Abdominal pain is becoming recognized as a widespread symptom as well, with one study reporting abdominal pain in 90\% of their 68 patients. ${ }^{2,3}$ Research on epidemiology was conducted in Olmsted County, Minnesota and reported the incidence, prevalence, and outcomes of Gp patients from 1996 to 2000. The incidence per 100,000 was 2.5 in men and 9.8 in women. The prevalence per 100,000 was 9.6 in men and 37.8 in women. Furthermore, patients with Gp had a significantly higher mortality than the rest of the population in that county. ${ }^{4}$ The conclusion of that study was while $\mathrm{Gp}$ is uncommon, patients have a recognized increase in health burdens.

\section{ETIOLOGY}

The majority of $\mathrm{Gp}$ cases can be classified into three main groups: idiopathic gastroparesis (IG, 36\%), diabetic gastroparesis (DG, 29\%), and postsurgical gastroparesis (PSG, 13\%) as seen in Table 1. ${ }^{1,5}$ Patients with IG, the most common etiology, are those who meet clinical and objective evidence of Gp without a primary identified cause. One important subset of IG is postviral; these patients have rapid onset of Gp symptoms after a viral prodromal phase. The classic history is a healthy patient

Table 1. Etiologies of Gastroparesis

Major etiologies of $\mathrm{Gp}$
Idiopathic gastroparesis
Diabetic gastroparesis
Postsurgical gastroparesis
Minor etiologies of $\mathrm{Gp}$
Parkinsonism
Amyloidosis
Paraneoplastic
Scleroderma
Mesenteric ischemia

Gp, gastroparesis.

\footnotetext{
Correspondence to: Thomas Abell

Division of Gastroenterology, Hepatology, and Nutrition, University of Louisville, 550 South Jackson Street, ACB3 A3L15, Louisville, KY 40202, USA

Tel: +1-502-852-6991, Fax: +1-502-852-0846, E-mail: thomas.abell@louisville.edu

Received on July 6, 2016. Accepted on September 9, 2016. Published online May 25, 2017

pISSN 1976-2283 eISSN 2005-1212 https://doi.org/10.5009/gnl16336

@ This is an Open Access article distributed under the terms of the Creative Commons Attribution Non-Commercial License (http://creativecommons.org/licenses/by-nc/4.0) which permits unrestricted non-commercial use, distribution, and reproduction in any medium, provided the original work is properly cited.
} 
with acute Gp symptoms such as nausea and vomiting without resolution of their symptoms. Typically these patients will improve over the course of a year. ${ }^{6}$ In comparison, DG is the most common identified cause of Gp. In a study examining 527 type I and type II diabetic patients, 5.2\% of type 1 diabetic and 1.0\% in type 2 diabetic patients developed Gp over the course of a 10 -year period. ${ }^{7}$ PSG is becoming a well-recognized complication of bariatric surgery for bypass and fundoplication for acid reflux. ${ }^{1}$ One study followed 615 patients for a year after Nissen fundoplication and found all patients had symptoms the first 3 months postoperatively. Early satiety (88\%), and bloating (64\%) were the most common symptoms, however $94 \%$ of patients had resolution of their symptoms a year after their operation. ${ }^{8}$ The other rare causes of $\mathrm{Gp}$ include diseases such as Parkinsonism, amyloidosis, paraneoplastic disease, scleroderma and mesenteric ischemia. The clinical guidelines of the American Journal of Gastroenterology recommend for patients with Gp to be screened for diabetes, thyroid dysfunction, neurological disease, bariatric surgery, and autoimmune disorders as possible underlying causes for $\mathrm{Gp}$.

\section{DIAGNOSIS}

The diagnosis of Gp requires an objective demonstration of delayed GE. The three methods are scintigraphy, wireless motility capsule (WMC), and carbon breath testing. Scintigraphy of a solid phase meal is still the most widely used and validated test for diagnosis. A consensus protocol was published in 2008 to standardize the test. It is recommended that diabetic patients should have their fasting glucose checked before the test and ideally should be $<275 \mathrm{mg} / \mathrm{dL}$. In addition, prokinetic agents (Metoclopramide, Erythromycin, and Domperidone), opiate medications, and anticholinergic agents (Bentyl, Levsin, and Robinul) should be stopped at least 2 days prior to the test to prevent interference. ${ }^{9}$ Patients should be fasting the previous night and have the test early morning and refrain from smoking during the test. A solid meal was emphasized as liquid studies correlated poorly with Gp symptoms. The recommended meal consists of a technetium (TC)-99m sulfur colloid radiolabeled meal with two large eggs, two slices of bread and jam, with water. An allergy to eggs is a contraindication. The entire meal or at least 50\% should be consumed. Imaging is then performed at $0,1,2$, and 4 hours after ingestion. Delayed GE was then defined at $>90 \%$ at 1 hour, $>60 \%$ at 2 hours, $>10 \%$ at 4 hours.
The test is most specific at the 4-hour mark, suggesting the need for studies to be continued for that length of time rather than relying on the 2-hour scan. In addition, patients with rapid emptying should be defined as $<30 \%$ retention after 1 hour. The GE study should also include the fasting blood sugar of diabetic patients, how much of the meal was ingested, the time, vomiting if it occurred, and medications taken in the last 24 hours to see if they affected the results. ${ }^{9}$ All of these recommendations were made to help provide a consensus protocol to help with physician and patient interpretation of results and increase reliability of the test.

One proposed method to increase standardization is the use of a WMC also called SmartPill which is able to measure $\mathrm{pH}$, temperature, and pressure. The SmartPill measures GE time based on the duration of time from ingestion to an abrupt rise in $\mathrm{pH}$ from the gastric baseline ( $>3 \mathrm{pH}$ units) which signifies the change from acidic antrum to the more alkaline duodenum. One study examined 148 patients (87 healthy patients, $61 \mathrm{Gp}$ patients) by having them ingest both the pill cam and doing a GE study. They found that at 4 hours the overall correlation between the two was $0.73 .^{10}$

Another noninvasive alternative is the use of ${ }^{13} \mathrm{C}$ labeled breath test using octanoate, which is a medium chain triglyceride which is mixed into a solid meal such as eggs or a muffin. The carbon labeled material is ingested and rapidly absorbed in the small intestine, transported to the liver by serum albumin, and oxidized to carbon dioxide which through respiration is eliminated. The rate limiting step of this process is GE. Analysis is done before ingestion and then every 15 minutes until 4 hours; delayed GE is if it takes more than 120 minutes for half of the radiolabeled material to be metabolized and excreted. Samples are measured using mass or infrared spectrometry. ${ }^{11,12}$ The current recommendation is that WMC and breath testing requires further study before it is considered as an equal alternative to a GE study, but its benefits of an in office procedure and lack of radiation help warrant further investigation. ${ }^{1}$

\section{GASTROPARESIS-LIKE SYNDROME}

An emerging concept proven by increasing evidence demonstrated by pathophysiology is gastroparesis-like syndrome (GLS). New groundbreaking research is revealing that GLS should be classified as a spectrum of Gp. ${ }^{13,14}$ Table 2 shows a quick reference comparing aspects of GLS and Gp. GLS helps to classify

Table 2. Comparison of Gastroparesis-Like Syndrome and Gastroparesis

\begin{tabular}{clllc}
\hline & GCSI scores & GE study & ICC & GES response \\
\hline GLS & No difference & Normal, rapid & Decreased & Therapeutic \\
Gp & No difference & Delayed & Decreased further & Therapeutic \\
\hline
\end{tabular}

GCSI, Gastric Cardinal Scoring Index; GE, gastric emptying; ICC, interstitial cells of Cajal; GES, gastric electrical stimulator; GLS, gastroparesis-like syndrome; $\mathrm{Gp}$, gastroparesis. 
patients who exhibit the symptoms of Gp but have a normal or rapid emptying study. One study examined 425 patients with chronic unexplained nausea and vomiting (CUNV) for at least 12 weeks without evidence of obstruction. Of those patients, 25\% percent had GE study that were normal or rapid (less than 30\% retention after an hour). The validated Gastroparesis Cardinal Symptom Index (GCSI) scale of severity (0-5) was used for both groups and at 48 weeks follow-up there was no difference in symptoms between Gp and CUNV patients. See Table 3 for the GCSI index. ${ }^{15}$ This begs the further question of how to classify patients exhibiting all the symptoms of Gp without an objective delayed GE study. These patients have also been shown to have a clinical course comparable to that of Gp patients and are proven to have a very similar burden of health. Research has shown that loss of neuronal nitric oxide synthase (nNOS) and loss of interstitial cells of Cajal (ICC) are the two most likely mechanisms that explain Gp. ${ }^{14,16,17}$ Further explanations of the physiology of these cells are described below. New studies involving gastric biopsies and ICC show that patients with CUNV have less ICC compared with healthy individuals. Gp have even fewer ICC. It is because of this correlative that CUNV should be characterized instead in part of a spectrum of Gp and subsequently termed GLS. ${ }^{18}$

\section{PATHOGENESIS}

The pathophysiology behind Gp has proven to be complicated, with multiple variables involved. Fundus and antral con-

Table 3. Gastroparesis Symptom Cardinal Index

\begin{tabular}{|c|c|c|c|c|c|c|}
\hline & None & Very mild & Mild & Moderate & Severe & Very severe \\
\hline 1. Nausea & 0 & 1 & 2 & 3 & 4 & 5 \\
\hline 2. Retching & 0 & 1 & 2 & 3 & 4 & 5 \\
\hline 3. Vomiting & 0 & 1 & 2 & 3 & 4 & 5 \\
\hline 4. Stomach fullness & 0 & 1 & 2 & 3 & 4 & 5 \\
\hline 5. Not able to finish a normal-sized meal & 0 & 1 & 2 & 3 & 4 & 5 \\
\hline 6. Feeling excessively full after meals & 0 & 1 & 2 & 3 & 4 & 5 \\
\hline 7. Loss of appetite & 0 & 1 & 2 & 3 & 4 & 5 \\
\hline 8. Bloating & 0 & 1 & 2 & 3 & 4 & 5 \\
\hline 9. Stomach or belly visibly larger & 0 & 1 & 2 & 3 & 4 & 5 \\
\hline
\end{tabular}

For each symptom, please circle the number that best describes how severe the symptom has been during the past 2 weeks. If you have not experienced this symptom, circle 0 .

Adapted from Revicki DA, et al. Aliment Pharmacol Ther 2003;18:141-150, with permission from John Wiley \& Sons. ${ }^{15}$

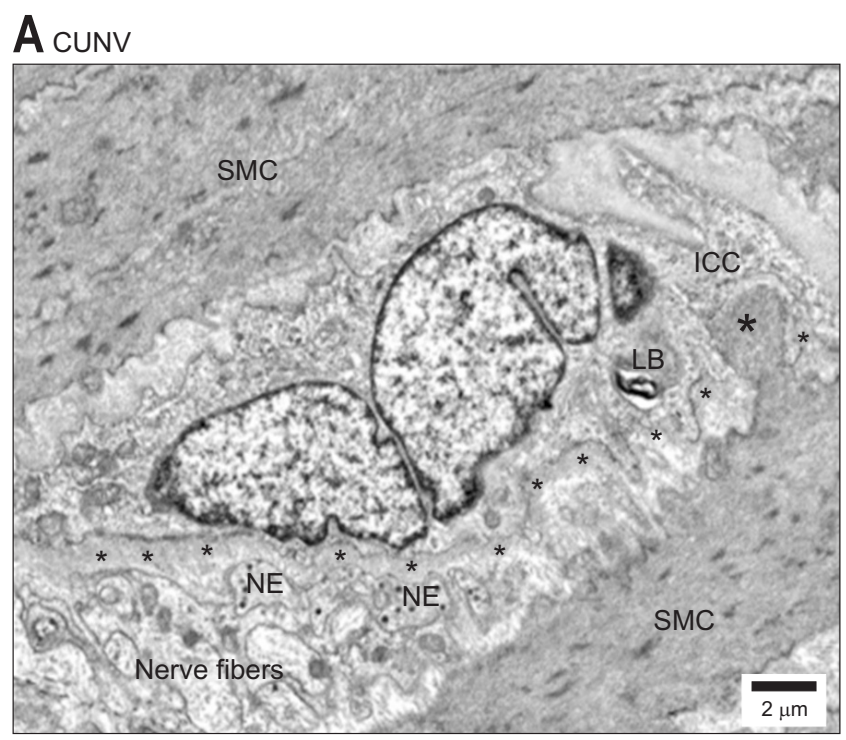

B control

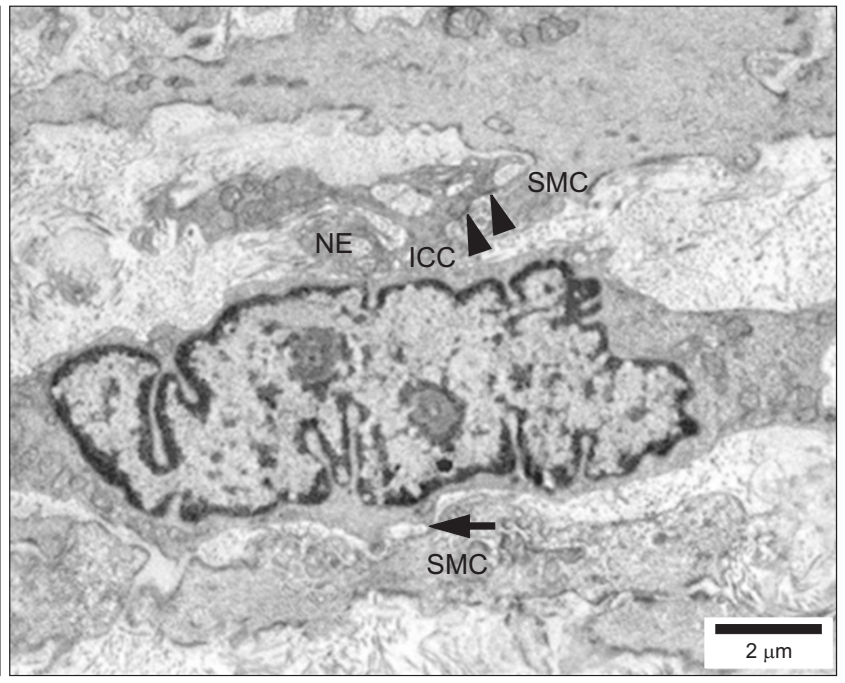

Fig. 1. Electron microscopy of the interstitial cells of Cajal (ICC) network in gastric smooth muscle in a chronic unexplained nausea and vomiting (CUNV) patient. (A) Compared with the control (B). Labeled structural components: thick basal lamina (small asterisks), nerve endings (NEs), smooth muscle cells (SMCs), lamellar body (LB), contact between ICC and SMCs (arrows), peg-and-socket junction (large asterisks). Adapted from Angeli TR, et al. Gastroenterology 2015;149:56-66.e5, with permission from Elsevier. ${ }^{18}$ 
tractions timed with relaxation of the pylorus in the stomach are coordinated between smooth muscle, autonomic nerves, and ICC. Fig. 1 demonstrates the histological changes that occur with loss of the connection between SMC and ICC. ${ }^{18}$ ICCs are the most recognized cells that function to regulate smooth muscle contractility through slow wave progression. They can be thought of as the cells that operate as the pacemakers in the gut; the slow waves initiated by ICC result in depolarization of L-type calcium channels resulting in contractile response. These cells are not just chronotropic but ionotropic as well, regulating the strength of the response. It is because of this relationship that research associating motility disorders with ICC are at the forefront of research. ICC cells are being studied across a multitude of motility pathology such as Hirschsprung's disease, achalasia, and pyloric stenosis. It is becoming increasingly apparent just how important ICC are for the regulation of intestinal motility. ${ }^{19}$

Examination for histological changes in Gp patients specifically examining ICC have been increasingly studied. Full thickness gastric biopsies obtained from the Gp Clinical Research Consortium, found that ICC cells were decreased. This pattern was seen in both IG and DG. This study consisted of 20 patients in each group of IG, DG, and a control group. In DG they found overwhelming results pointing to ICC correlating with Gp compared to the control group. Patients with DG had only $2.8 \pm 0.4$ ICC per high power field versus $5.3 \pm 0.2$, with a $p<0.0001$. In addition, lower ICC correlated with slower emptying scans. There was a similar correlation in IG patients as well. ${ }^{20}$

The ICC cells interact with enteric nerves that produce inhibitory and excitatory signals to help regulate smooth muscle and contractility. The study of neuronal changes from these signals has been of great interest as well. Stimuli that promote contraction, such as acetylcholine and substance P, are important for motility. Inhibition of these contractions have been studied as well, specifically nNOS which produces nitric oxide. Fig. 2 shows the interaction between ICC and nNOS for normal GE. Studies done on mice with knockouts for Nos1, which codes for nNOS, demonstrated that the mice developed gastric stasis. Pharmacologic inhibition of nNOS was consistent for delayed GE in mice as well. The results of that study showed that the mechanism behind nitric oxide signaling is the inhibition of duodenal and pyloric contractions. ${ }^{21-23}$ Furthermore, in diabetic and streptozoticin-induced diabetic rats, nNOS expression was decreased along with delayed GE. ${ }^{24,25}$

Further examining DG, there are new studies looking at the role of systemic inflammation. One study examined 143 patients with DM and symptoms of Gp and found that C-reactive protein, an inflammatory marker, was associated with increased symptoms. ${ }^{26}$ Another study strongly supporting the role of inflammation in DG examined full thickness gastric biopsies in 28 patients. Six of 14 patients with DG had evidence of a lymphocytic infiltrate in the myenteric plexus as opposed to controls who had no lymphocytic infiltrate. Once again a decrease in ICC was seen as well. ${ }^{27}$

One pilot study examined the idea of immunotherapy to target the inflammatory role of Gp. This study examined 11 patients with refractory $\mathrm{Gp}$ that was resistant to drug and stimulators, and treated the patients with either intravenous immunoglobulin (IVIG), mycophenolate mofetil (MMF), or a combination of methylprednisolone and MMF for 8 to 12 weeks. Symptoms were scored and the study found that patients responded well to IVIG with the most improvement in vomiting symptoms. ${ }^{28}$ Another similar study was done with 23 patients suspected of having an autoimmune component to their gastrointestinal (GI) dysmotility. Seventeen out of 23 patients in this study improved and involved IVIG as the main therapy along with a few patients receiving methylprednisolone or combination. ${ }^{29}$ These two studies illustrate the importance of considering an autoimmune etiology and subsequent inflammatory response, especially in patients who have been refractory to medications and stimulators.

Disruptions of the autonomic nervous system (ANS) have also been well-recognized, with previously mentioned gastric biopsies showing a decrease in ICC and enteric neuronal stimulation. One study proposed the effect of the ANS on gastric stimulation by both a cholinergic and andrenergic response with evidence utilized from heart rate monitoring and electrogastrogram in five patients with DG. ${ }^{30,31}$ Studies are even looking at correlating gastric electrical stimulation to the central nervous system (CNS) in rats. ${ }^{32}$ These studies help to further emphasize prospective studies on ANS, CNS, and enteric pathways should be monitored in their role of pyloric, antrum and GE.

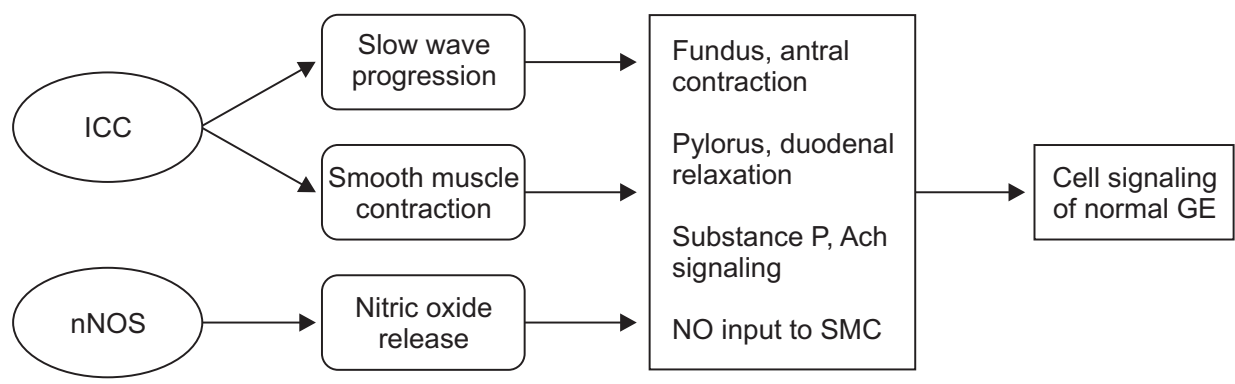

Fig. 2. Interaction of interstitial cells of Cajal (ICC) cells and neuronal nitric oxide synthase (nNOS) signaling for normal gastric emptying (GE). NO, nitric oxide; Ach, acetylcholine; SMC, smooth muscle cell. 


\section{TREATMENT}

The treatment of Gp requires wide consideration of multiple factors to best optimize care for the patient. Each patient should have a thorough evaluation of the past remedies and approaches to help tailor their future management. Optimizing oral nutrition should be the main goal. As discussed, the complex pathogenesis involving the CNS, ANS, inflammatory and neuromuscular dysfunction all contribute to management. See
Fig. 3 for this complex interaction. The severity of Gp should always be assessed and one commonly used questionnaire is the validated GCSI. ${ }^{15}$ A severity index has also been created classifying patients as either grade 1-mild Gp, grade 2-compensated $\mathrm{Gp}$, and grade 3-Gp with gastric failure, in order of severity. See Table 4 for this outcome score. ${ }^{33}$ Several studies have also supported use of patient-reported outcomes as correlating with severity of the disease. This tool has been shown to be useful as well in helping providers assess the current state of treatment

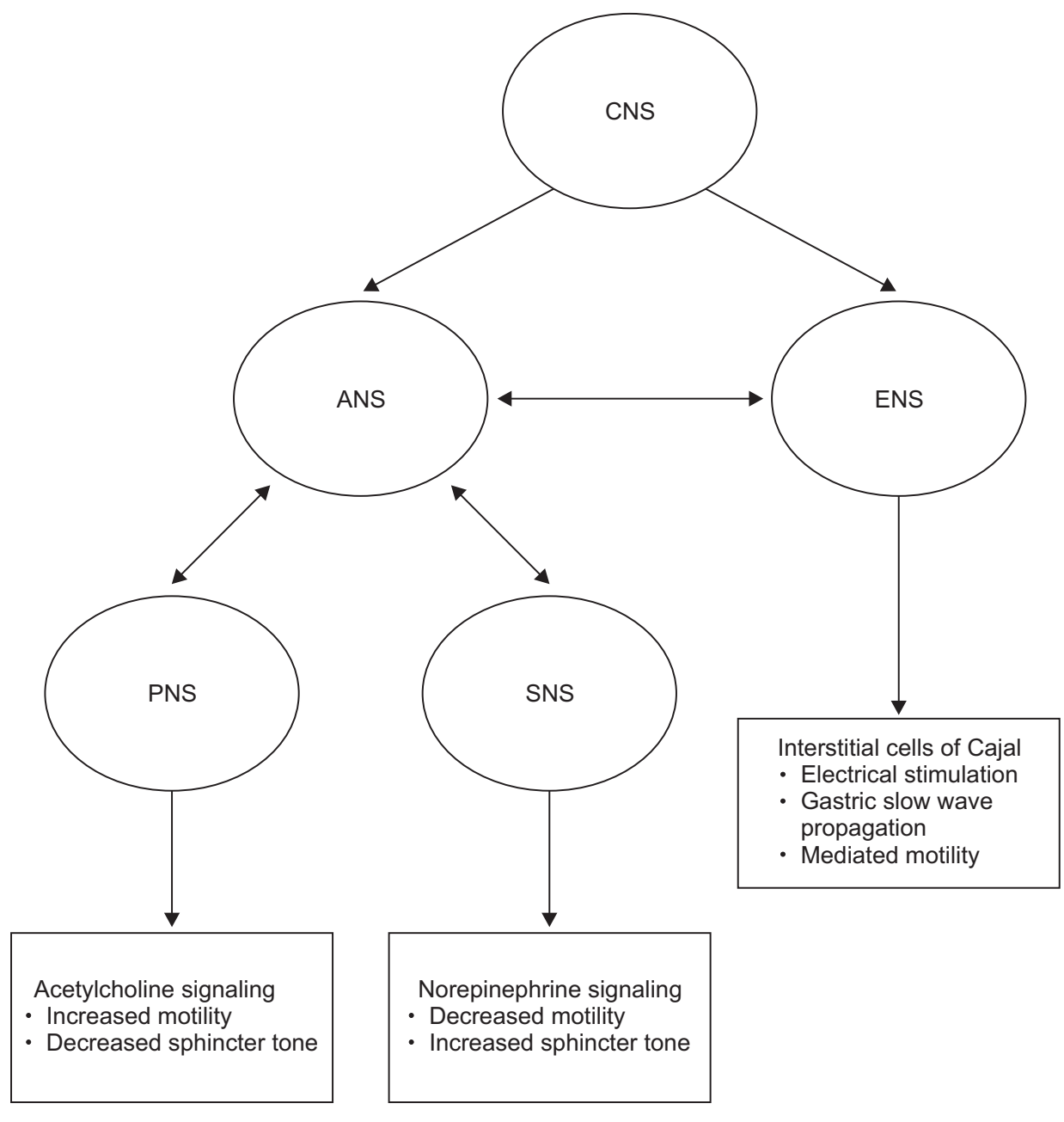

Fig. 3. Conceptual framework for pathophysiology of gastroparesis syndromes.

CNS, central nervous system; ANS, autonomic nervous system; ENS, enteric nervous system; PNS, parasympathetic nervous system; SNS, sympathetic nervous system.

Table 4. Patient-Reported Gastrointestinal Outcomes and Total Symptom Score

\begin{tabular}{lccc}
\hline \multicolumn{1}{c}{ Symptom } & Frequency & Severity & Average \\
\hline Vomiting & 01234 & 01234 & 01234 \\
Nausea & 01234 & 01234 & 01234 \\
Anorexia/early satiety & 01234 & 01234 & 01234 \\
Bloating/distension & 01234 & 01234 & 01234 \\
Abdominal pain & 01234 & 01234 & 01234 \\
Total GI symptom score & Sum of above & Sum of above & Sum of above \\
\hline
\end{tabular}

The total symptom score instrument is used as a patient-reported outcomes tool. Rated as 0 to 4 , none to worse and total (0-20). GI, gastrointestinal.

Adapted from Cutts T, et al. BMC Gastroenterol 2016;16:107.33 
and whether adjustments should be made. ${ }^{33,34}$ The hallmarks of treatment are to correct nutritional deficiencies, decrease symptoms, and pursue the etiology in the hopes of rectifying the underlying cause of Gp. Combination strategies that focus on these three principles are the key strategies for management. More than 10\% unintentional weight loss over a 6 month period signifies severe malnutrition. ${ }^{35}$ Please refer to Fig. 4 for a quick algorithm for the diagnosis and management of gastroparesis syndromes.

\section{Diet}

Diet modification is essential to help improve symptoms and should be emphasized as part of the treatment plan. Diets should consist of multiple small meals and should be limited in their fat and fiber content since those tend to delay emptying. Meal frequency should have a goal of at least 4 to 6 meals, and supplementation with high caloric liquids can help with nutrition without causing symptoms in mild Gp. Food should be chewed well and consumed in small-portioned bites. Supplementation

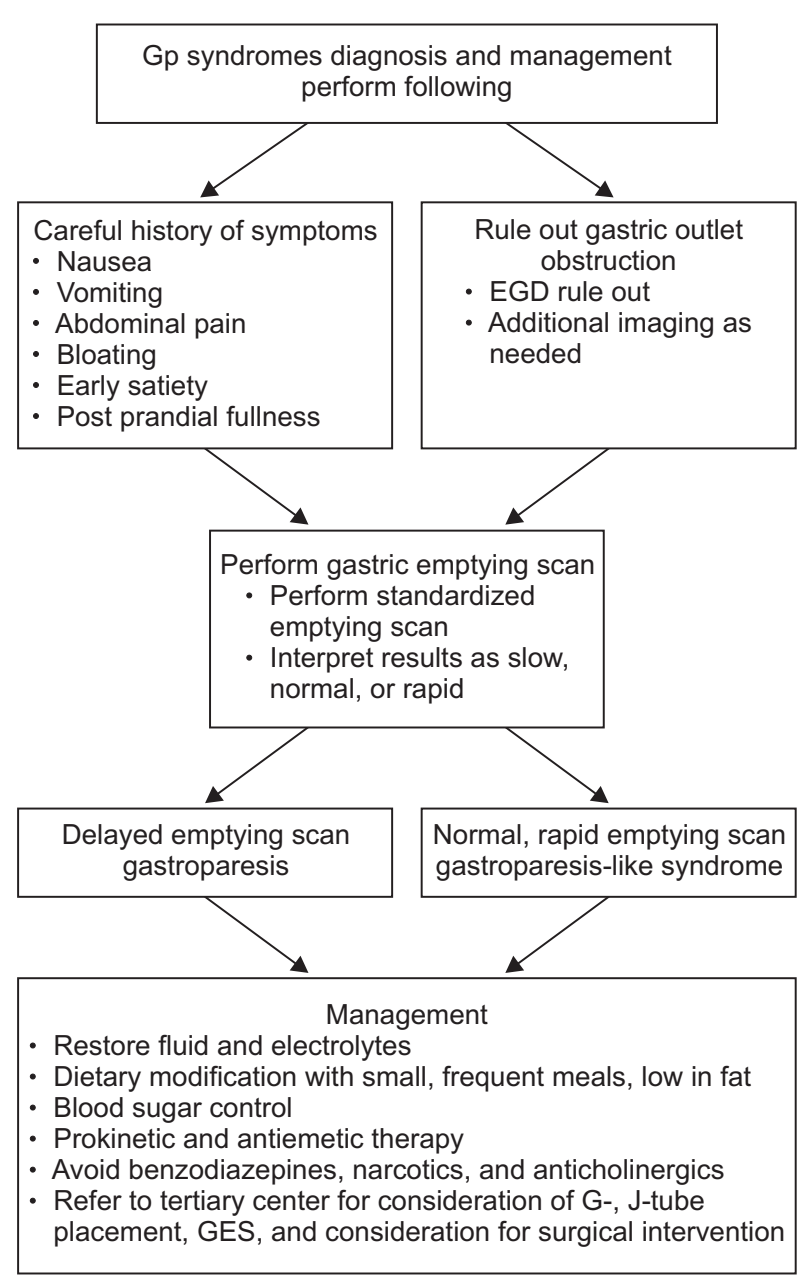

Fig. 4. Diagnosis and management algorithm for gastroparesis (Gp) syndromes.

EGD, esophagogastroduodenoscopy; GES, gastric electrical stimulators. with a multivitamin is helpful as well if tolerated. A comprehensive diet history should also be performed and foods that seem to aggravate $\mathrm{Gp}$ in the specific patient should be avoided, such as dairy or certain meats. Patients with a high intolerance of liquid supplementation may signal that tolerance of solid food will be even more difficult. ${ }^{36,37}$ A few studies have even shown alcoholic beverages, carbonated drinks, and cigarette smoking should be avoided as modifiable factors that affect emptying. In addition, heavy lipid containing foods should also be avoided since they potentially also slow down emptying. ${ }^{38-40}$

\section{Enteral nutrition}

For patients who are having difficulties with oral nutrition, enteral nutrition using a jejunostomy feeding tube may be the preferred solution. A naso-jejunal (NJ) tube should be placed first to see if enteral feeding past the stomach helps with the symptoms. Nasogastric tubes and gastrostomy tubes are not recommended since symptoms of Gp still persist and the risk of aspiration for pneumonia is higher. NJ tube feeding should start slow at 25 to $50 \mathrm{~mL}$ an hour using feeds consisting of 1.5 calories per $\mathrm{mL}$ and advanced as tolerated by 10 to $25 \mathrm{~mL}$ an hour. ${ }^{41,42}$ Feeding should be done continuously 24 hours a day until nutrition improves where the patient can tolerate an oral diet better with the eventual goal to have nocturnal feeding to allow for normal daily activities. Enteral feeding should be the preferred method over total parenteral nutrition (TPN), which should be avoided if possible. TPN can cause complications with infection, access problems, and thrombosis, and may only be necessary if dysmotility involves the small bowel to help provide supplemental nutritional support. Parenteral support should be the last resort. ${ }^{43}$

\section{Hyperglycemia}

Besides focusing on nutrition, regulation of blood sugar should be extremely important as well to help reduce the symptoms of Gp. Poor glycemic control inhibits GE and even interferes with emptying tests. Numerous studies have shown GI symptoms manifesting in patients who already have other diabetic complications such as neuropathy and retinopathy. ${ }^{44-46}$ Especially in type 1 diabetics, blood glucose levels between 288 and $360 \mathrm{mg} / \mathrm{dL}$ have been shown to inhibit both solid and liquid emptying. ${ }^{44}$ Even in healthy individuals without Gp symptoms, acute hyperglycemia induces reduction of antral motor activity. Furthermore, correlation between increases in glucose alongside increases in symptoms of post-prandial fullness. ${ }^{47}$ All of these studies illustrate that glycemic control is important in optimization of Gp care in the reduction of symptoms and motility.

\section{Prokinetic medications}

Prokinetic medications have long been a mainstay of treatment. Dopamine receptor antagonists work by inhibiting the effects of dopamine on GE and also as a serotonin antagonist as 
well to help with nausea. Metoclopramide is the only U.S. Food and Drug Administration (FDA) approved dopamine receptor antagonist specifically approved for the treatment of Gp. Studies comparing metoclopramide versus placebo improvements in Gp symptoms showed it helped decrease delayed emptying on scintigraphy. ${ }^{48-50}$ Metoclopramide is available in intravenous, intramuscular, oral, and liquid form and carries a black box warning of tardive dyskinesia. The intravenous form is more often used in hospitalized patients suffering from Gp. Metoclopramide has also been shown to increase symptoms of drug-induced parkinsonism, and akathisia compared to controls. Other side effects such as fatigue and drowsiness may limit the tolerance for the medication in up to $30 \%$ of patients. Increases in prolactin stimulation from dopamine antagonism can cause galactorrhea and menstrual irregularities in women. Increasing doses affect the incidence of these symptoms so starting at a low dose of 5 mg 3 times a day (tid) before meals and titrating up as tolerated is recommended. ${ }^{1,35,51,52}$ Maximum dose is $40 \mathrm{mg} /$ day and the drug should not be used for more than 12 weeks without careful consideration of the risks and benefits due to the extra pyramidal side effects. Reduction of the doses and skipping days as tolerated should be encouraged to help limit symptoms.

Domperidone is also a dopamine receptor antagonist with the same efficacy but known for less extrapyramidal side effects compared to Metoclopramide since it does not cross the bloodbrain barrier with starting doses of $10 \mathrm{mg}$ tid with titration up to $20 \mathrm{mg}$ tid and at bedtime. Max doses of $80 \mathrm{mg}$ to $120 \mathrm{mg}$ a day may be needed for at least 1 month to determine the efficacy of the medication. One study examined the medication's effects in Parkinson's patients and found that it reduced GI symptoms from levodopa therapy and accelerated GE of solid meals. Therefore, the medication is great for Parkinson's patients with Gp symptoms. The main concern for the medication is QT prolongation and should not be given if the corrected QT is longer than $470 \mathrm{~ms}$ in males and 450 in females so an electrocardiogram should be performed. ${ }^{1,53,54}$ Unfortunately the medication is not FDA approved in the United States and obtaining the medication from other countries is discouraged by the FDA. An approved method would be through a FDA investigational new drug application with signature of informed consent and then subsequent purchase through an FDA-approved pharmacy. ${ }^{35}$ Another drug like Metoclopramide and Domperidone is Itopride, which has been studied for use in patients with dyspepsia and $\mathrm{Gp}$, but more studies are needed to validate its use. Itopride is also currently not FDA approved for use. ${ }^{55-57}$

Another approach to treatment is targeting motilin receptors. Motilin is a peptide hormone that promotes activation of smooth muscle in L-type calcium channels. Macrolide antibiotics have agonistic effects on these motilin receptors and help with GE. ${ }^{58}$ Studies on the prokinetic effects of Erythromycin have been positive even when compared against Metoclopramide. ${ }^{59}$ In hospitalized diabetic patients, a dose of $3 \mathrm{mg} / \mathrm{kg}$ every 8 hours by IV was shown to be helpful. In double blind studies, administration by IV was shown to normalize GE for solids and liquids. ${ }^{60}$ Studies examining both IG and DG patients on chronic oral Erythromycin showed improved emptying 4 weeks from the beginning of treatment. ${ }^{61}$ The drawbacks to motilin medications are the down regulation of motilin receptor with the effect of tachyphylaxis. This affect can happen within days of administration, so close monitoring and titration of oral Erythromycin is needed for therapeutic purposes. Lowest effective doses are recommended. Problems with cytochrome P450 interactions can also limit the use of the medication and cause more symptoms and carries a risk of sudden cardiac death as well. ${ }^{35}$ Another macrolide antibiotic, Azithromycin, has been shown to be equally effective as Erythromycin but without the cardiac risk and cytochrome interactions. Studies with Azithromycin have shown increased antral contractility with medication and a longer half-life than Erythromycin. ${ }^{62-65}$ There is a need for further investigation of chronic use of Azithromycin for use in Gp. Other motilin receptor agonists that are not antibiotics are currently being investigated for use as well. One agent called Mitemcinal appears to increase antral contractility. A few randomized, double blind studies with placebo and multiple different doses of Mitemcinal showed increased emptying in both DG and IG. ${ }^{66-69}$ The potential for benefit compared to the macrolide antibiotics is a decrease in side effects such as QT prolongation. One earlier motilin agonist, ABT-229, unfortunately was not proven to help with $\mathrm{Gp}^{70}$

\section{5. $5 \mathrm{HT}_{4}$-receptor agonists}

Cisapride is a $5 \mathrm{HT}_{4}$ receptor agonist that leads to acetylcholine release and subsequent antral contraction and increased GE. ${ }^{71-73}$ It was initially FDA approved but was subsequently removed after cardiac arrhythmias developed due to QT prolongation and was removed in 2000. Tegaserod is also a $5 \mathrm{HT}_{4}$ agonist and has already been in use in the treatment of constipation in irritable bowel syndrome and has been shown to help with GE. The advantage of Tegaserod was that it did not have the QT prolonging effects that Cisapride has. One study published the use of the Tegaserod in critically ill patients with impaired motility with resolution within 24 hours of administration. ${ }^{74,75}$ Further studies with larger sample sizes need to be completed to determine if Tegaserod could have a greater impact in Gp patients; however, Tegaserod is also not easily obtained.

\section{Antiemetic therapy}

Antiemetic agents have widely varying mechanisms and their use is recommended as second line behind the previously mentioned prokinetic agents such as Metoclopramide. The most common used drugs are phenothiazines (Prochlorperazine), antihistamines (Promethazine), and $5-\mathrm{HT}_{3}$ receptor antagonists (Ondansetron). These medications all carry side effects such as QT prolongation. Studies examining Ondansetron have shown 
that it is not superior to Metoclopramide or Promethazine in patients when presenting to the emergency department and also are associated with QT prolongation. ${ }^{35,76}$ Studies also examined tricyclic antidepressants (TCA) in Gp. Due to the anticholinergics effects of TCA's they could potentially worsen symptoms and cause further decreased GE. ${ }^{77,78}$ These anti emetic agents, while commonly dispensed to hospitalized patients, should be considered only after failure of prokinetic agents in Gp.

\section{Gastric electrical stimulators}

Gastric electrical stimulators (GES), have been approved for use by the FDA for drug-refractory IG and DG. The device is directly implanted into the stomach. For patients who are refractory to medications, GES has been proposed as a therapeutic option. The device consists of electrodes surgically placed into the anterior wall of the stomach, which are connected to a pulse generator. An early study in 2002 examined 38 patients with significant symptoms of $\mathrm{Gp}$ and found that 33 of them responded very well to temporary GES stimulation and underwent permanent stimulators. Patients were followed for a year and 97\% experienced a reduction in symptoms of nausea and vomiting and the average weight gain was 5.5\%. ${ }^{79}$ The most important aspect is that long-term data also showed a decrease in morbidity from Gp even 10 years after placement of the stimulator. Remarkably, hospitalizations, medications required, and symptoms were all decreased $(p<0.05)$. The study involved DG, IG, and postsurgical Gp patients and all three groups saw weight increases after stimulation implantation. Even more astounding was that $89 \%$ of these patients were able to tolerate nutrition well enough to have their J-tube removed. ${ }^{80}$ With such great results a comparison of GES versus medical management was completed. Eighteen patients were enrolled, nine in the GES arm and nine in the medical management arm and parameters, symptoms, and hospital costs were compared after these patients were followed for 3 years. ${ }^{81}$

The role of GES has even been investigated in the treatment of patients with GLS, which as mentioned previously have nondelayed gastric scintigraphy. One large study of 551 patients examined temporary GES placement after an emptying scan was performed. Patients were then classified into three groups: delayed emptying, normal emptying, and rapid emptying. Patients in all three subgroups had improvements in symptom scores; this demonstrates that patients with GLS should also be considered for stimulators and further supports the belief that GLS is part of the spectrum of Gp. ${ }^{82}$

\section{Surgical treatments}

Besides GES, other modes of surgeries are being explored that aim to anatomically reduce resistance to GE. Surgical procedures range from pyloroplasty to partial or total gastrectomy to help bypass the stomach. One article reviewed surgical procedures for Gp and came to the conclusion that gastrectomy and long-term outcomes of Gp need to be further studied since only 26 subjects in two trials had been reviewed. ${ }^{83}$ Clinical guidelines for surgery are for patients who are being severely affected by Gp where risk of renal failure and shortened life expectancy is severely limited, with the intention to relieve effects of nausea and vomiting. ${ }^{1}$ One alternative, less invasive surgery than gastrectomy is laparoscopic pyloroplasty. One study involved 28 patients who underwent minimally invasive pyloroplasty, and saw improvements in GES times, symptom scores, and medication use; $83 \%$ of the patients improved..$^{84}$ Overall, more research studies on surgical treatments for Gp need to be conducted to determine the long-term outcome and possibly to help identify those patients most at risk with mortality from Gp who have already tried traditional prokinetic and antiemetic therapies.

\section{CONCLUSIONS}

Progress has been made in the last few decades in understanding the pathophysiology of $\mathrm{Gp}$ and in the various treatment plans. The focus at the cellular level and function of cells that cause gastric dysfunction are key to understanding the pathogenesis of this disease. The term gastroparesis-like syndrome was created to help classify those patients who have all the symptoms of $\mathrm{Gp}$ without the objective decreased emptying scan. Ultimately, some of these patients may progress to Gp considering the progression of disease relating to the number of ICC cells seen. Some drug-refractory Gp patients have even been shown to benefit from GES. Other drug and device resistant patients may be helped with immunotherapy. Progress towards understanding the pathophysiology of patients with Gp syndromes may help us treat patients with such profound symptoms that affect their quality of life.

\section{CONFLICTS OF INTEREST}

Thomas Abell is a speaker and investigator for Medtronic, is an investigator for Theravance and has IP through the University of Mississippi, now licensed to ADEPT-GI, of which he is the founder. He is also an editor for MedStudy and a reviewer for UpToDate. Nanlong Liu has no conflicts of interest to disclose.

\section{ACKNOWLEDGEMENTS}

The authors would like to thank Catherine McBride at the University of Louisville for help with manuscript preparation and formatting.

\section{REFERENCES}

1. Camilleri M, Parkman HP, Shafi MA, Abell TL, Gerson L; American College of Gastroenterology. Clinical guideline: management of gastroparesis. Am J Gastroenterol 2013;108:18-37. 
2. Cherian D, Parkman HP. Nausea and vomiting in diabetic and idiopathic gastroparesis. Neurogastroenterol Motil 2012;24:217-222. e103.

3. Cherian D, Sachdeva P, Fisher RS, Parkman HP. Abdominal pain is a frequent symptom of gastroparesis. Clin Gastroenterol Hepatol 2010;8:676-681.

4. Jung HK, Choung RS, Locke GR 3rd, et al. The incidence, prevalence, and outcomes of patients with gastroparesis in Olmsted County, Minnesota, from 1996 to 2006. Gastroenterology 2009; 136:1225-1233.

5. Hyett B, Martinez FJ, Gill BM, et al. Delayed radionucleotide gastric emptying studies predict morbidity in diabetics with symptoms of gastroparesis. Gastroenterology 2009;137:445-452.

6. Bityutskiy LP, Soykan I, McCallum RW. Viral gastroparesis: a subgroup of idiopathic gastroparesis--clinical characteristics and long-term outcomes. Am J Gastroenterol 1997;92:1501-1504.

7. Choung RS, Locke GR 3rd, Schleck CD, Zinsmeister AR, Melton LJ 3rd, Talley NJ. Risk of gastroparesis in subjects with type 1 and 2 diabetes in the general population. Am J Gastroenterol 2012; 107:82-88.

8. Frantzides CT, Carlson MA, Zografakis JG, Moore RE, Zeni T, Madan AK. Postoperative gastrointestinal complaints after laparoscopic Nissen fundoplication. JSLS 2006;10:39-42.

9. Abell TL, Camilleri M, Donohoe K, et al. Consensus recommendations for gastric emptying scintigraphy: a joint report of the American Neurogastroenterology and Motility Society and the Society of Nuclear Medicine. J Nucl Med Technol 2008;36:44-54.

10. Kuo B, McCallum RW, Koch KL, et al. Comparison of gastric emptying of a nondigestible capsule to a radio-labelled meal in healthy and gastroparetic subjects. Aliment Pharmacol Ther 2008;27:186-196.

11. Bruno G, Lopetuso LR, Ianiro G, et al. 13C-octanoic acid breath test to study gastric emptying time. Eur Rev Med Pharmacol Sci 2013;17 Suppl 2:59-64.

12. Maes BD, Ghoos YF, Geypens BJ, et al. Combined carbon-13-glycine/carbon-14-octanoic acid breath test to monitor gastric emptying rates of liquids and solids. J Nucl Med 1994;35:824-831.

13. Pasricha PJ, Colvin R, Yates K, et al. Characteristics of patients with chronic unexplained nausea and vomiting and normal gastric emptying. Clin Gastroenterol Hepatol 2011;9:567-576.e4.

14. Bashashati M, McCallum RW. Motility: is 'ICC-opathy' present in gastroparesis-like syndrome? Nat Rev Gastroenterol Hepatol 2015;12:375-376.

15. Revicki DA, Rentz AM, Dubois D, et al. Development and validation of a patient-assessed gastroparesis symptom severity measure: the Gastroparesis Cardinal Symptom Index. Aliment Pharmacol Ther 2003;18:141-150.

16. Camilleri M, Bharucha AE, Farrugia G. Epidemiology, mechanisms, and management of diabetic gastroparesis. Clin Gastroenterol Hepatol 2011;9:5-12.

17. Oh JH, Pasricha PJ. Recent advances in the pathophysiology and treatment of gastroparesis. J Neurogastroenterol Motil 2013;19:18-
24.

18. Angeli TR, Cheng LK, Du P, et al. Loss of interstitial cells of Cajal and patterns of gastric dysrhythmia in patients with chronic unexplained nausea and vomiting. Gastroenterology 2015;149:5666.e5.

19. Farrugia G. Interstitial cells of Cajal in health and disease. Neurogastroenterol Motil 2008;20 Suppl 1:54-63.

20. Grover M, Bernard CE, Pasricha PJ, et al. Clinical-histological associations in gastroparesis: results from the Gastroparesis Clinical Research Consortium. Neurogastroenterol Motil 2012;24:531-539. e249.

21. Vittal H, Farrugia G, Gomez G, Pasricha PJ. Mechanisms of disease: the pathological basis of gastroparesis: a review of experimental and clinical studies. Nat Clin Pract Gastroenterol Hepatol 2007;4:336-346.

22. Orihata M, Sarna SK. Inhibition of nitric oxide synthase delays gastric emptying of solid meals. J Pharmacol Exp Ther 1994;271:660-670.

23. Plourde V, Quintero E, Suto G, Coimbra C, Taché Y. Delayed gastric emptying induced by inhibitors of nitric oxide synthase in rats. Eur J Pharmacol 1994;256:125-129.

24. Takahashi T, Nakamura K, Itoh H, Sima AA, Owyang C. Impaired expression of nitric oxide synthase in the gastric myenteric plexus of spontaneously diabetic rats. Gastroenterology 1997;113:15351544.

25. Wrzos HF, Cruz A, Polavarapu R, Shearer D, Ouyang A. Nitric oxide synthase (NOS) expression in the myenteric plexus of streptozotocin-diabetic rats. Dig Dis Sci 1997;42:2106-2110.

26. Sarker S, Ahmad N, Kedar A, et al. T2063 Inflammatory and hematologic disorders are associated with GI symptoms in diabetic gastroparesis. Gastroenterology 2010;138(5 Supple 1):S-624.

27. Harberson J, Thomas RM, Harbison SP, Parkman HP. Gastric neuromuscular pathology in gastroparesis: analysis of full-thickness antral biopsies. Dig Dis Sci 2010;55:359-370.

28. Soota K, Kedar A, Nikitina Y, Arendale E, Vedanarayanan V, Abell TL. Immunomodulation for treatment of drug and device refractory gastroparesis. Results Immunol 2016;6:11-14.

29. Flanagan EP, Saito YA, Lennon VA, et al. Immunotherapy trial as diagnostic test in evaluating patients with presumed autoimmune gastrointestinal dysmotility. Neurogastroenterol Motil 2014;26:1285-1297.

30. Zárate N, Mearin F, Wang XY, Hewlett B, Huizinga JD, Malagelada JR. Severe idiopathic gastroparesis due to neuronal and interstitial cells of Cajal degeneration: pathological findings and management. Gut 2003;52:966-970.

31. Stocker A, Abell TL, Rashed H, Kedar A, Boatright B, Chen J. Autonomic evaluation of patients with gastroparesis and neurostimulation: comparisons of direct/systemic and indirect/cardiac measures. Gastroenterology Res 2016;9:10-16.

32. Qin C, Sun Y, Chen JD, Foreman RD. Gastric electrical stimulation modulates neuronal activity in nucleus tractus solitarii in rats. Auton Neurosci 2005;119:1-8. 
33. Cutts T, Holmes S, Kedar A, Beatty K, K Mohammad M, Abell T. Twenty-five years of advocacy for patients with gastroparesis: support group therapy and patient reported outcome tool development. BMC Gastroenterol 2016;16:107.

34. Kedar A, McElmurray L, Abell TL. Sa1332 Bloating and abdominal pain symptoms may be important indicators of disease status in patients with severe dyspepsia or gastroparesis. Gastroenterology 2014;146(5 Supple 1):S-265.

35. Abell TL, Bernstein RK, Cutts T, et al. Treatment of gastroparesis: a multidisciplinary clinical review. Neurogastroenterol Motil 2006;18:263-283.

36. Bouras EP, Scolapio JS. Gastric motility disorders: management that optimizes nutritional status. J Clin Gastroenterol 2004;38:549557.

37. Parrish CR, Yoshida CM. Nutrition intervention for the patient with gastroparesis: an update. Pract Gastroenterol 2005;29:29-66.

38. Sanaka M, Anjiki H, Tsutsumi H, et al. Effect of cigarette smoking on gastric emptying of solids in Japanese smokers: a crossover study using the 13C-octanoic acid breath test. J Gastroenterol 2005;40:578-582.

39. Pfeiffer A, Högl B, Kaess H. Effect of ethanol and commonly ingested alcoholic beverages on gastric emptying and gastrointestinal transit. Clin Investig 1992;70:487-491.

40. Camilleri M. Appraisal of medium- and long-term treatment of gastroparesis and chronic intestinal dysmotility. Am J Gastroenterol 1994;89:1769-1774.

41. Maple JT, Petersen BT, Baron TH, Gostout CJ, Wong Kee Song LM, Buttar NS. Direct percutaneous endoscopic jejunostomy: outcomes in 307 consecutive attempts. Am J Gastroenterol 2005;100:26812688.

42. Fontana RJ, Barnett JL. Jejunostomy tube placement in refractory diabetic gastroparesis: a retrospective review. Am J Gastroenterol 1996;91:2174-2178.

43. Parkman HP, Hasler WL, Fisher RS; American Gastroenterological Association. American Gastroenterological Association technical review on the diagnosis and treatment of gastroparesis. Gastroenterology 2004;127:1592-1622.

44. Fraser RJ, Horowitz M, Maddox AF, Harding PE, Chatterton BE, Dent J. Hyperglycaemia slows gastric emptying in type 1 (insulindependent) diabetes mellitus. Diabetologia 1990;33:675-680.

45. Bytzer P, Talley NJ, Hammer J, Young LJ, Jones MP, Horowitz M. GI symptoms in diabetes mellitus are associated with both poor glycemic control and diabetic complications. Am J Gastroenterol 2002;97:604-611.

46. Schvarcz E, Palmér M, Aman J, Horowitz M, Stridsberg M, Berne C. Physiological hyperglycemia slows gastric emptying in normal subjects and patients with insulin-dependent diabetes mellitus. Gastroenterology 1997;113:60-66.

47. Jones KL, Horowitz M, Berry M, Wishart JM, Guha S. Blood glucose concentration influences postprandial fullness in IDDM. Diabetes Care 1997;20:1141-1146.

48. McCallum RW, Ricci DA, Rakatansky H, et al. A multicenter placebo-controlled clinical trial of oral metoclopramide in diabetic gastroparesis. Diabetes Care 1983;6:463-467.

49. Snape WJ Jr, Battle WM, Schwartz SS, Braunstein SN, Goldstein HA, Alavi A. Metoclopramide to treat gastroparesis due to diabetes mellitus: a double-blind, controlled trial. Ann Intern Med 1982;96:444-446.

50. Sturm A, Holtmann G, Goebell H, Gerken G. Prokinetics in patients with gastroparesis: a systematic analysis. Digestion 1999;60:422-427.

51. Ganzini L, Casey DE, Hoffman WF, McCall AL. The prevalence of metoclopramide-induced tardive dyskinesia and acute extrapyramidal movement disorders. Arch Intern Med 1993;153:1469-1475.

52. Bateman DN, Rawlins MD, Simpson JM. Extrapyramidal reactions with metoclopramide. Br Med J (Clin Res Ed) 1985;291:930-932.

53. Soykan I, Sarosiek I, Shifflett J, Wooten GF, McCallum RW. Effect of chronic oral domperidone therapy on gastrointestinal symptoms and gastric emptying in patients with Parkinson's disease. Mov Disord 1997;12:952-957.

54. Patterson D, Abell T, Rothstein R, Koch K, Barnett J. A doubleblind multicenter comparison of domperidone and metoclopramide in the treatment of diabetic patients with symptoms of gastroparesis. Am J Gastroenterol 1999;94:1230-1234.

55. Basque JR, Kikuchi Y, Ohtsubo T, Sarashina G, Nakamura H. Efficacy of itopride hydrochloride on gastric emptying in patients with diabetic gastroparesis. Am J Gastroenterol 2005;100:S325.

56. Talley NJ, Tack J, Ptak T, Gupta R, Giguère M. Itopride in functional dyspepsia: results of two phase III multicentre, randomised, double-blind, placebo-controlled trials. Gut 2008;57:740-746.

57. Stevens JE, Russo A, Maddox AF, et al. Effect of itopride on gastric emptying in longstanding diabetes mellitus. Neurogastroenterol Motil 2008;20:456-463.

58. Weber FH Jr, Richards RD, McCallum RW. Erythromycin: a motilin agonist and gastrointestinal prokinetic agent. Am J Gastroenterol 1993;88:485-490.

59. Erbas T, Varoglu E, Erbas B, Tastekin G, Akalin S. Comparison of metoclopramide and erythromycin in the treatment of diabetic gastroparesis. Diabetes Care 1993;16:1511-1514.

60. Richards RD, Davenport K, McCallum RW. The treatment of idiopathic and diabetic gastroparesis with acute intravenous and chronic oral erythromycin. Am J Gastroenterol 1993;88:203-207.

61. Janssens J, Peeters TL, Vantrappen G, et al. Improvement of gastric emptying in diabetic gastroparesis by erythromycin. Preliminary studies. N Engl J Med 1990;322:1028-1031.

62. Larson JM, Tavakkoli A, Drane WE, Toskes PP, Moshiree B. Advantages of azithromycin over erythromycin in improving the gastric emptying half-time in adult patients with gastroparesis. J Neurogastroenterol Motil 2010;16:407-413.

63. Potter TG, Snider KR. Azithromycin for the treatment of gastroparesis. Ann Pharmacother 2013;47:411-415.

64. Chini P, Toskes PP, Waseem S, Hou W, McDonald R, Moshiree B. Effect of azithromycin on small bowel motility in patients with gastrointestinal dysmotility. Scand J Gastroenterol 2012;47:422- 
427.

65. Moshiree B, McDonald R, Hou W, Toskes PP. Comparison of the effect of azithromycin versus erythromycin on antroduodenal pressure profiles of patients with chronic functional gastrointestinal pain and gastroparesis. Dig Dis Sci 2010;55:675-683.

66. McCallum RW, Cynshi 0; Investigative Team. Clinical trial: effect of mitemcinal (a motilin agonist) on gastric emptying in patients with gastroparesis: a randomized, multicentre, placebo-controlled study. Aliment Pharmacol Ther 2007;26:1121-1130.

67. Takanashi H, Cynshi 0. Motilides: a long and winding road: lessons from mitemcinal (GM-611) on diabetic gastroparesis. Regul Pept 2009;155:18-23.

68. McCallum RW, Cynshi 0; US Investigative Team. Efficacy of mitemcinal, a motilin agonist, on gastrointestinal symptoms in patients with symptoms suggesting diabetic gastropathy: a randomized, multi-center, placebo-controlled trial. Aliment Pharmacol Ther 2007;26:107-116.

69. Fang J, McCallum R, DiBase J, Schmitt C, Kipnes M. Effect of mitemcinal fumarate (GM-611) on gastric emptying in patients with idiopathic or diabetic gastroparesis. Gastroenterology 2004;126(4 Suppl 2):A483.

70. Talley NJ, Verlinden M, Snape W, et al. Failure of a motilin receptor agonist (ABT-229) to relieve the symptoms of functional dyspepsia in patients with and without delayed gastric emptying: a randomized double-blind placebo-controlled trial. Aliment Pharmacol Ther 2000;14:1653-1661.

71. Fraser RJ, Horowitz M, Maddox AF, Dent J. Postprandial antropyloroduodenal motility and gastric emptying in gastroparesis: effects of cisapride. Gut 1994;35:172-178.

72. Corinaldesi R, Stanghellini V, Raiti C, Rea E, Salgemini R, Barbara L. Effect of chronic administration of cisapride on gastric emptying of a solid meal and on dyspeptic symptoms in patients with idiopathic gastroparesis. Gut 1987;28:300-305.

73. Richards RD, Valenzuela GA, Davenport KG, Fisher KL, McCallum RW. Objective and subjective results of a randomized, doubleblind, placebo-controlled trial using cisapride to treat gastroparesis. Dig Dis Sci 1993;38:811-816.
74. Banh HL, MacLean C, Topp T, Hall R. The use of tegaserod in critically ill patients with impaired gastric motility. Clin Pharmacol Ther 2005;77:583-586.

75. Crowell MD, Mathis C, Schettler VA, Yunus T, Lacy BE. The effects of tegaserod, a 5-HT receptor agonist, on gastric emptying in a murine model of diabetes mellitus. Neurogastroenterol Motil 2005; 17:738-743.

76. Gralla RJ, Itri LM, Pisko SE, et al. Antiemetic efficacy of high-dose metoclopramide: randomized trials with placebo and prochlorperazine in patients with chemotherapy-induced nausea and vomiting. N Engl J Med 1981;305:905-909.

77. Prakash C, Clouse RE. Cyclic vomiting syndrome in adults: clinical features and response to tricyclic antidepressants. Am J Gastroenterol 1999;94:2855-2860.

78. Sawhney MS, Prakash C, Lustman PJ, Clouse RE. Tricyclic antidepressants for chronic vomiting in diabetic patients. Dig Dis Sci 2007;52:418-424.

79. Abell TL, Van Cutsem E, Abrahamsson H, et al. Gastric electrical stimulation in intractable symptomatic gastroparesis. Digestion 2002;66:204-212.

80. McCallum RW, Lin Z, Forster J, Roeser K, Hou Q, Sarosiek I. Gastric electrical stimulation improves outcomes of patients with gastroparesis for up to 10 years. Clin Gastroenterol Hepatol 2011;9: 314-319.e1.

81. Cutts TF, Luo J, Starkebaum W, Rashed H, Abell TL. Is gastric electrical stimulation superior to standard pharmacologic therapy in improving GI symptoms, healthcare resources, and long-term health care benefits? Neurogastroenterol Motil 2005;17:35-43.

82. Singh S, McCrary J, Kedar A, et al. Temporary endoscopic stimulation in gastroparesis-like syndrome. J Neurogastroenterol Motil 2015;21:520-527.

83. Jones MP, Maganti K. A systematic review of surgical therapy for gastroparesis. Am J Gastroenterol 2003;98:2122-2129.

84. Hibbard ML, Dunst CM, Swanström LL. Laparoscopic and endoscopic pyloroplasty for gastroparesis results in sustained symptom improvement. J Gastrointest Surg 2011;15:1513-1519. 